\title{
BMJ Open COVID-19 and 'immune boosting' on the internet: a content analysis of Google search results
}

\author{
Christen Rachul (D) , ${ }^{1}$ Alessandro R Marcon (D) , ${ }^{2}$ Benjamin Collins (D) ,1,3 \\ Timothy Caulfield ${ }^{2,4}$
}

To cite: Rachul $C$,

Marcon AR, Collins B, et al. COVID-19 and 'immune boosting' on the internet: a content analysis of Google search results. BMJ Open 2020;10:e040989. doi:10.1136/ bmjopen-2020-040989

- Prepublication history and additional material for this paper are available online. To view these files, please visit the journal online (http://dx.doi. org/10.1136/bmjopen-2020040989).

Received 27 May 2020

Revised 03 October 2020

Accepted 16 0ctober 2020

Check for updates

(C) Author(s) (or their employer(s)) 2020. Re-use permitted under CC BY-NC. No commercial re-use. See rights and permissions. Published by BMJ.

${ }^{1}$ Rady Faculty of Health Sciences, University of Manitoba, Winnipeg, Manitoba, Canada

${ }^{2}$ Health Law Institute, University of Alberta, Edmonton, Alberta, Canada

${ }^{3}$ Department of Anthropology, University of Manitoba, Winnipeg, Manitoba, Canada

${ }^{4}$ Faculty of Law, University of Alberta, Edmonton, Alberta, Canada

Correspondence to Dr Christen Rachul; christen.rachul@umanitoba.ca

\section{ABSTRACT}

Objective The spread of misinformation has accompanied the coronavirus pandemic, including topics such as immune boosting to prevent COVID-19. This study explores how immune boosting is portrayed on the internet during the COVID-19 pandemic.

Design Content analysis.

Methods We compiled a dataset of 227 webpages from Google searches in Canada and the USA using the phrase 'boost immunity' AND 'coronavirus' on 1 April 2020. We coded webpages for typology and portrayal of immune boosting and supplements. We recorded mentions of microbiome, whether the webpage was selling or advertising an immune boosting product or service, and suggested strategies for boosting immunity.

Results No significant differences were found between webpages that appeared in the searches in Canada and the USA. The most common types of webpages were from news $(40.5 \%)$ and commercial $(24.7 \%)$ websites. The concept of immune boosting was portrayed as beneficial for avoiding COVID-19 in $85.5 \%$ of webpages and supplements were portrayed as beneficial in $40 \%$ of the webpages, but commercial sites were more likely to have these portrayals. The top immune boosting strategies were vitamin C (34.8\%), diet (34.4\%), sleep (34.4\%), exercise $(30.8 \%)$ and zinc $(26.9 \%)$. Less than $10 \%$ of the webpages provide any critique of the concept of immune boosting. Conclusions Pairing evidence-based advice for maintaining one's health (eg, healthy diet, exercise, sleep) with the phrase immune boosting and strategies lacking in evidence may inadvertently help to legitimise the concept, making it a powerful marketing tool. Results demonstrate how the spread of misinformation is complex and often more subtle than blatant fraudulent claims.

\section{INTRODUCTION}

The coronavirus pandemic has been accompanied by the spread of misinformation on topics that include the marketing of and speculation on possible cures, treatments and preventative strategies. Some scholars have noted that this 'infodemic'-as WHO called it-has already resulted in considerable harm. ${ }^{1-4}$ Specifically, this infodemic is associated with deaths, delayed treatment, wasted resources and substantive concerns that it

\section{Strengths and limitations of this study}

The study includes a large dataset of webpages that appear in Google searches in Canada and the USA during a critical period in the pandemic.

- Data analysis identifies and characterises a common coronavirus-related prevention strategy in a range of online contexts.

- Inter-rater reliability of coding was high with strong to almost perfect agreement

- Dataset represented English-language webpages only based on a specific query conducted at two points in time in two regions.

- Internet protocol (IP) address masking was not possible and some localised results may have appeared in search results for the two regions.

adds to an already confused and chaotic information environment. ${ }^{5-7}$

Boosting the immune system is a common theme associated with many of the products and practices presented as strategies to avoid or help fight COVID-19. Indeed, a Google Trends analysis reveals that searches for phrases like 'immune boost' and 'immune boosting' spiked in early February, 2020, as concern about the impact of the virus started to intensify. However, the concept of immune boosting is misleading and scientifically inaccurate. ${ }^{89}$ The immune system is fantastically complex, and researchers are still exploring how various nutrients impact its performance, with overly active immune systems potentially leading to autoimmune diseases and anaphylaxis. Some early research studies have also suggested that an exaggerated immune response is implicated in respiratory failure in patients with COVID-19. ${ }^{10}$ There is no evidence that any product or practiceaside from a vaccine-will provide extra or enhanced 'immune boosting' protection against COVID-19.

Despite this reality, celebrities, wellness gurus and supplement companies have 
been making claims about the need and ways to boost our immune system. ${ }^{11}$ These popularisations are entangled with the general public's belief that supplements improve a body's immune system, ${ }^{12}{ }^{13}$ resulting in immune boosting becoming commonly associated with pop culture representations of COVID-19. Additionally, there is some evidence that the kinds of COVID-19 information that people are exposed to affects their health-related behaviours and attitudes. ${ }^{14}{ }^{15}$ As such, the different public responses to the pandemic in Canada and the USA warrant further exploration of how misinformation may impact on perceptions of how to prevent and protect against COVID-19. ${ }^{16} 17$ This study, therefore, focuses on how immune boosting and supplements are being portrayed with respect to COVID-19 in Canada and the USA.

\section{METHODS}

\section{Data collection}

Following Cassa Macedo et al, ${ }^{18}$ we conducted searches on www.google.com using the Google Chrome browser, the most widely used search engine, ${ }^{19}$ using the phrase 'boost immunity' AND 'coronavirus' on 1 April 2020 in Winnipeg, Canada to compile a dataset of uniform resource locators (URLs) for analysis. To limit personalisation of the search results, we did not link the browser to an existing Google account, and we deleted cookies and erased the browser history. We conducted advanced searches, which allowed us to select regional settings. We first conducted a search with the region set to Canada, then deleted all cookies and erased the browsing history, and conducted the same search the region set to the USA.

We transferred the URLs from each search result to an Microsoft Excel spread sheet, noting the country and result number. Google Chrome automatically omits similar results, so we collected all of the URLs for each search until we reached the automatically generated message 'In order to show you the most relevant results, we have omitted some entries very similar to the [\#] already displayed. If you like, you can repeat the search with the omitted results included.' After, visiting and reading each webpage, we excluded 35 URLs because they were irrelevant (ie, not about immune boosting and/or coronavirus), behind a paywall, or inaccessible (ie, broken links). The resulting data set consisted of 227 webpages.

\section{Content analysis}

We conducted a modified content analysis of the webpages ${ }^{20}$ using a coding framework similar to previous studies conducted by our team that includes both deductive and inductive category development. ${ }^{21-25}$ Only the content on the webpage linked to the URL was coded. We first coded the typology of the websites in which the webpages appeared using a modified version of Cassa Macedo et al s typology (see online supplemental table A) ${ }^{18}$ Webpages were then coded for how immune boosting and supplements were portrayed, whether an immune boosting product or service was being sold or advertised on the webpage, and whether the microbiome or gut health was mentioned. For webpages that portrayed immune boosting as beneficial to preventing COVID-19, we recorded the suggested immune boosting strategies, that is, the actions people can take to boost their immune systems. Webpages that suggested taking vitamins and minerals (eg, vitamin $\mathrm{C}$, zinc) through food and/or supplements were coded for those specific vitamins or minerals, not food or supplement. Similarly, we recorded an immune boosting strategy as 'supplements and vitamins' when the webpage made a general reference to these types of products or in reference to taking a multivitamin or supplement with multiple immune boosting ingredients.

Two coders analysed the entire data set of URLs. To determine reliability of coding, a third coder coded the subjective items in a sample of 45 URLs, $\sim 20 \%$ of the data set. Intercoder reliability was calculated for these items. Cohen's kappa for typology of the website, portrayal of immune boosting and portrayal of supplements were calculated at $0.886,0.900,0.962$ respectively, demonstrating strong to almost perfect agreement. ${ }^{26}$ An audit of the immune boosting strategies was conducted by the third coder to determine accuracy. Disagreements were discussed between two coders, CR and ARM, until agreement was reached.

\section{Statistical analysis}

Data were analysed using descriptive statistics in SPSS V.25. We used the $\chi^{2}$ test to compare website typologies and portrayals, to compare results from the search in Canada and the search in the USA, and to compare the top 20 search results generated by each search with the remaining webpages in the data set, since the top 20 search results have a higher chance of being read. ${ }^{27}$

\section{Patient and public involvement}

This research was done without patient or public involvement. Patients or members of the public were not invited to comment on the study design and were not consulted to interpret the results. Patients or members of the public were not invited to contribute to the writing or editing of this document for readability or accuracy.

\section{RESULTS}

The search in Canada yielded 171 websites and the search in the USA yielded 173 websites, with 117 URLs overlapping, 54 URLs being unique to the Canadian search and 56 being unique to the US search. For results associated with the top 20 search hits, we include the webpages that appear in the top 20 search results of at least one of the regional searches, for a total of 25 webpages.

The two primary types of websites were news and commercial websites (table 1). While there were no significant differences found between the webpages that 
Table 1 Typology of websites

\begin{tabular}{lllll}
\hline Typology & All websites, \% & Top 20 results, \% & Canada, \% & USA, \% \\
\hline News & $92(40.5)$ & $13(52)$ & $76(44.4)$ & $70(40.5)$ \\
Commercial & $56(24.7)$ & $4(16)$ & $40(23.4)$ & $43(24.9)$ \\
Other & $20(8.8)$ & $1(4)$ & $9(5.3)$ & $18(10.4)$ \\
Magazine & $19(8.4)$ & $2(8)$ & $16(9.4)$ & $14(8.1)$ \\
Blog & $15(6.6)$ & $1(4)$ & $13(7.6)$ & $9(5.2)$ \\
Health portal & $12(5.3)$ & $1(4)$ & $8(4.7)$ & $8(4.6)$ \\
Non-profit organisation & $4(1.8)$ & $2(5)$ & $3(1.8)$ & $4(2.3)$ \\
Professionals & $4(1.8 \%)$ & 0 & $2(1.2)$ & $4(2.3)$ \\
Scientific journals & $3(1.3)$ & 0 & $2(1.2)$ & $2(1.2)$ \\
Government or governing body & $2(0.9)$ & $1(4)$ & $2(1.2)$ & $1(0.6)$ \\
\hline
\end{tabular}

appeared in the top 20 search results and the webpages in the rest of the data set $\left(X^{2}(9, \mathrm{n}=227)=13.06, \mathrm{p}=0.160\right)$, news sites made up over $50 \%$ of the websites that appeared in the top 20 search results, while commercial sites only made up $16 \%$. No significant differences were found in the results between Canada and the USA for website typology $\left(X^{2}(9, n=344)=5.35, p=0.803\right)$. In many cases, the typology of websites was difficult to discern, as evidenced by the high number of websites coded as 'other', and many sites exhibited characteristic features of more than one typology, for example, a news-style website that was advertising a specific immune boosting supplement. Therefore, we also coded whether the webpage was selling or advertising a specific product or service related to immune boosting. About $20 \%$ of the webpages $(n=48)$ were selling or advertising a specific product.

We coded the webpages for whether the concept of immune boosting was portrayed as neutral, whether the website noted the lack of evidence for the concept of immune boosting, or whether the website stated that immune boosting was beneficial for preventing COVID-19 (table 2). Over $85 \%$ of webpages portrayed the concept of immune boosting as beneficial, with less than $10 \%$ of the webpages critiquing the concept of immune boosting and its lack of evidence. There was a significant difference between the top 20 search results and the remaining data set $\left(X^{2}(2, n=227)=6.93 \mathrm{p}=0.031\right)$ with $72 \%$ of webpages in the top 20 search results and $87.1 \%$ of the remaining webpages in the data set portraying immune boosting as beneficial. There were no significant differences between webpages that appeared in the searches in Canada and the US $\left(X^{2}(2, \mathrm{n}=344)=1.24, \mathrm{p}=0.538\right)$.
We also coded each webpage for portrayal of supplements as a way to boost immunity (table 3 ). Almost half of the webpages did not refer to supplements and were coded as neutral, but $40 \%$ of the webpages portrayed supplements as beneficial to boosting immunity, highlighting that when supplements were mentioned it was largely in a positive fashion. There were no significant differences between the top 20 search results and the rest of the data set $\left(X^{2}(2, n=227)=0.041, p=0.980\right)$ nor between the Canada and US search results $\left(X^{2}(2\right.$, $\mathrm{n}=344)=0.98, \mathrm{p}=0.614$ ).

We included the microbiome or gut health within our coding framework as it was frequently mentioned in relation to immune boosting. Over $30 \%(n=70)$ of webpages mentioned the microbiome or gut health, which was generally intertwined within the narrative of immune boosting, and emphasised its importance for overall health. For example, one webpage states, "Yoghurt is considered a probiotic that is essential to your immune system's health. It directly affects your gut, helping the good bacteria to thrive. Your gut health is directly associated with your immune system. Therefore, a healthy gut means a healthy immune system." 28

To assess the degree to which different types of webpages represent the concept of immune boosting, we compared website typology with the portrayal of immune boosting and supplements, mention of the microbiome or gut health, and whether the webpage was selling or advertising an immune boosting product or service. We focused on news and commercial websites given their prevalence in the dataset and due to low case counts for the other types of websites. Commercial webpages were

Table 2 Portrayal of immune boosting

\begin{tabular}{llccc}
\hline & All websites, \% & Top 20 results, \% & Canada, \% & USA, \% \\
\hline Neutral & $12(5.3)$ & $4(16)$ & $11(6.4)$ & $8(4.6)$ \\
Notes lack of evidence & $21(9.3)$ & $3(12)$ & $18(10.5)$ & $14(8.1)$ \\
States beneficial & $194(85.5)$ & $18(72)$ & $142(83)$ & $151(87.3)$ \\
\hline
\end{tabular}


Table 3 Portrayal of supplements

\begin{tabular}{lllll}
\hline & All websites, \% & Top 20 results, \% & Canada, \% & USA, \% \\
\hline Neutral & $109(48)$ & $12(48)$ & $85(49.7)$ & $77(44.5)$ \\
Notes lack of evidence & $27(11.9)$ & $3(12)$ & $19(11.1)$ & $20(11.6)$ \\
States beneficial & $92(40)$ & $10(40)$ & $67(39.2)$ & $76(43.9)$ \\
\hline
\end{tabular}

significantly more likely to portray immune boosting $\left(X^{2}(2, \mathrm{n}=148)=11.56, \mathrm{p}=0.003\right)$ and supplements $\left(X^{2}\right.$ $(2, \mathrm{~N}=148)=14.77, \mathrm{p}=0.001)$ as beneficial compared with news webpages (table 4). In addition, 58.9\% ( $\mathrm{n}=33)$ of commercial webpages and $5.4 \%(n=5)$ of news webpages were selling or advertising a product, which was statistically significant $\left(X^{2}(1, n=148)=52.20, p \leq 0.0001\right)$. Finally, $39.3 \%(n=22)$ of commercial webpages and $25 \%(n=23)$ of news webpages mention the microbiome or gut health, which was not statistically significant $\left(X^{2}(1, n=148)=3.36\right.$, $\mathrm{p}=0.067$ ).

We coded 83 different strategies that were suggested as a way to boost immunity. Figure 1 shows the strategies that appeared in more than $10 \%$ of the total dataset of webpages. The most common strategies-vitamin C $(n=79)$, sleep $(n=78)$ and diet $(n=78)$-appeared in almost $35 \%$ of the webpages. In contrast, the most common strategies in the top 20 search results are sleep $(\mathrm{n}=11)$, diet $(\mathrm{n}=10)$ and exercise $(\mathrm{n}=9)$, which appeared in $44 \%, 40 \%$ and $36 \%$ of these websites, respectively.

\section{DISCUSSION}

Our study highlights the dominance of the concept of immune boosting during this global pandemic with no major differences in how the concept is portrayed in Canada and the USA. A large portion of the webpages $(85.5 \%)$ portray immune boosting as beneficial, providing no critical scientific content and explicitly or implicitly suggesting the efficacy of boosting the immune system. In comparison to previous studies that find a large presence of commercial websites, ${ }^{1829}$ less than a quarter of the websites in our dataset $(24.7 \%)$ are commercial, and only $20 \%$ of webpages were selling a specific immune boosting product or service. It is possible that Google may have modified their search rank algorithms during the pandemic to foreground established media sources and institutions over commercial discourse, but to our knowledge there has been no official statement from Google addressing this. However, $40 \%$ of webpages portrayed supplements, such as vitamins, as beneficial for boosting immunity, which indirectly supports a hugely popular multibillion dollar industry ${ }^{30-32}$ with largely no scientific basis to support the 'immune boost' claim. ${ }^{8}$ Similarly, while others found that commercial websites were somewhat hidden further down in search results, ${ }^{1828}$ there were only minor variations in the types of websites and how the webpages portrayed immune boosting and supplements between the whole data set and the webpages that appeared in the top 20 of search results.

Despite many of the webpages citing supplements as beneficial to boosting the immune system, diet, sleep, exercise and stress reduction are some of the most common strategies suggested. Eating a balanced diet, getting sufficient sleep, exercising regularly and reducing one's stress levels are well known to be strategies for maintaining health under any circumstances. However, the explanations from webpages for how these strategies prevent COVID-19 are framed as not just for health, but for boosting immunity. This suggests that the concept of 'immune boosting' has taken on a broader meaning and seems to be deployed to attract interest in the products or ideas being put forth. The phrase is now ubiquitous and has likely taken on a 'health halo', ${ }^{33}$ not unlike other wellness terms that lack clear definition or health benefits, such as 'natural', or 'gluten-free'. ${ }^{34} 35$ The microbiome or gut health were also mentioned as an important part of boosting immunity in $30.8 \%$ of the webpages. This is an example of using the rhetoric around an emerging area of science to legitimise unproven approaches to health-a tactic that has been deployed in other contexts. ${ }^{3637}$

The reification of the phrase 'immune boosting' when paired with solid advice for maintaining one's health (eg, healthy diet, exercise, sleep) and with language from genuine areas of science, such as microbiome research, may inadvertently help to legitimise the concept, making it a more potent marketing tool. Diet, sleep, and exercise are among the top five strategies suggested in commercial webpages and the microbiome is mentioned in $39.3 \%$ of commercial webpages, which means that immune boosting strategies that lack evidence are often

Table 4 Comparison of news and commercial website portrayals

\begin{tabular}{llllll}
\hline & \multicolumn{3}{l}{ Immune boosting } & \multicolumn{2}{l}{ Supplements } \\
\cline { 2 - 3 } \cline { 5 - 5 } & News, $\%$ & Commercial, $\%$ & & News, \% & Commercial, \% \\
\hline Neutral & $5(5.4)$ & 0 & $51(55.4)$ & $18(32.1)$ \\
Notes lack of evidence & $18(19.6)$ & $2(3.6)$ & $16(17.4)$ & $5(8.9)$ \\
States beneficial & $69(75)$ & $54(96.4)$ & $25(27.2)$ & $33(58.9)$ \\
\hline
\end{tabular}




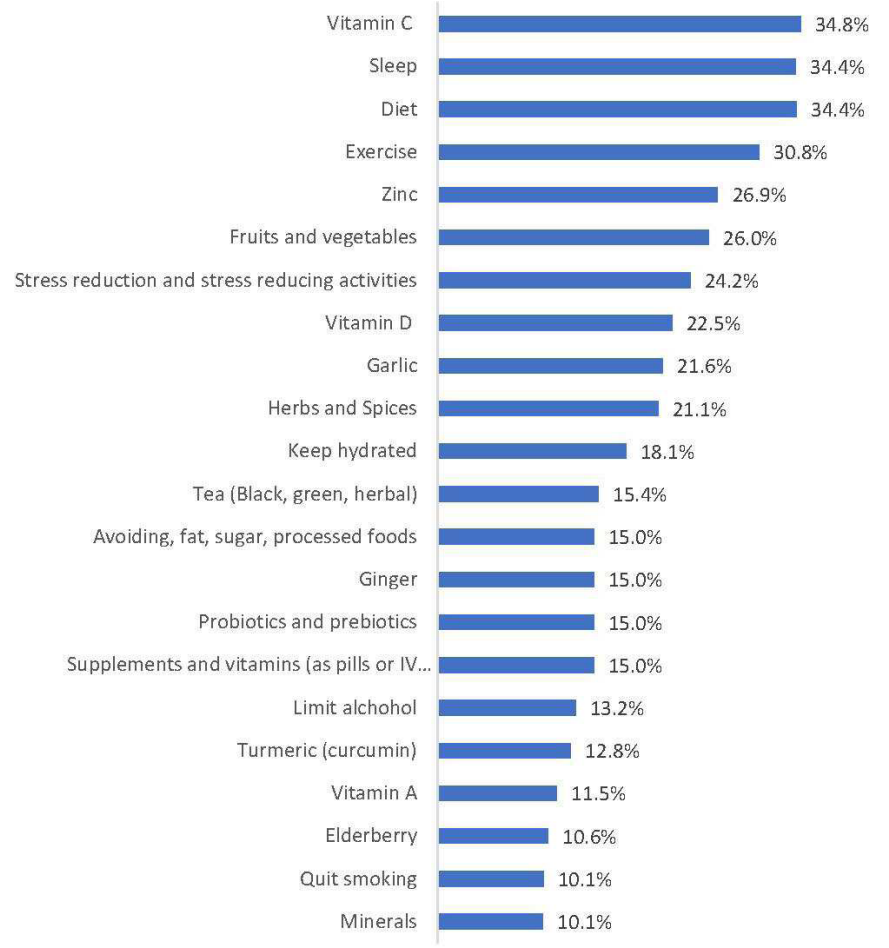

$\begin{array}{llllllllll}0 \% & 5 \% & 10 \% & 15 \% & 20 \% & 25 \% & 30 \% & 35 \% & 40 \%\end{array}$

Figure 1 Immune boosting strategies ( $>10 \%$ of webpages).

described on par, or in association, with sound advice for maintaining health with little to indicate the difference to readers. This framing forms one of the core kinds of misinformation portrayed by the immune boosting narrative. It is often an implied, rather than explicit, form of misinformation-where the context and associations to other health actions or relevant science suggest efficacy and benefit. Perhaps more troubling are the advertisements of products and services intertwined within this immune boosting narrative. Policy responses-including regulatory action-will need to grapple with these less overt forms of health misinformation.

\section{Limitations}

Our study has some limitations. First, we made all efforts to limit the personalisation of google searches and to approximate searches in different regions, but IP address masking was not possible and some localised results may have appeared in search results. Second, the searches were conducted in a single day at two points in time. Subsequent searches at different points in time during the pandemic may have yielded a different data set. The data set also includes only English-language websites.

\section{CONCLUSION}

The results from our study demonstrate how the spread of misinformation is complex and often more subtle than blatant fraudulent claims. The public is increasingly going online for health information ${ }^{38}$ and questions persist around the kinds of inaccurate information the public is absorbing and the impacts it may be having on health-related decisions and actions. It is unknown, for example, whether large numbers of the North American public have felt that strengthening their immune system has allowed them to participate in less social distancing. Further research is required on the impact of immune boosting messages on public perceptions and subsequent health-related behaviours. Also unclear is whether immune boosting ideas have clashed with the messaging from public health experts. This study demonstrates, however, that in the case of pandemic like COVID-19 conflictive messaging exists online and presents significant challenges for the public seeking scientifically accurate information and advice.

Acknowledgements The authors would like to thank Robyn Hyde-Lay for support for this project.

Contributors CR, ARM and TC conceived of the study. CR compiled the dataset and $C R, A R M$ and $B C$ analysed the data. All authors were involved in interpreting the data, drafting the manuscript, revising the manuscript critically for intellectual content, and approving the final version to be published and agreed to be accountable for all aspects of the work.

Funding The authors would also like to thank the Canadian Institutes for Health Research, Alberta Innovates, the Ministry of Economic Development, Trade and Tourism, the Government of Alberta, the Government of Canada, Genome Canada and Genome Alberta for their generous support of the following projects: (1) Coronavirus Outbreak: Mapping and Countering Misinformation; (2) Critical Thinking in the Digital Age: Countering Coronavirus Misinformation and (3) Childhood Asthma and the Microbiome - Precision Health for Life: The CHILD Study.

Competing interests None declared.

Patient consent for publication Not required.

Provenance and peer review Not commissioned; externally peer reviewed.

Data availability statement Data are available in a public, open access repository. The data set is available at https://doi.org/10.6084/m9.figshare.12783644.

Supplemental material This content has been supplied by the author(s). It has not been vetted by BMJ Publishing Group Limited (BMJ) and may not have been peer-reviewed. Any opinions or recommendations discussed are solely those of the author(s) and are not endorsed by BMJ. BMJ disclaims all liability and responsibility arising from any reliance placed on the content. Where the content includes any translated material, BMJ does not warrant the accuracy and reliability of the translations (including but not limited to local regulations, clinical guidelines, terminology, drug names and drug dosages), and is not responsible for any error and/or omissions arising from translation and adaptation or otherwise.

Open access This is an open access article distributed in accordance with the Creative Commons Attribution Non Commercial (CC BY-NC 4.0) license, which permits others to distribute, remix, adapt, build upon this work non-commercially, and license their derivative works on different terms, provided the original work is properly cited, appropriate credit is given, any changes made indicated, and the use is non-commercial. See: http://creativecommons.org/licenses/by-nc/4.0/.

\section{ORCID iDs}

Christen Rachul http://orcid.org/0000-0002-3726-1891

Alessandro R Marcon http://orcid.org/0000-0001-5018-423X

Benjamin Collins http://orcid.org/0000-0002-2416-3184

\section{REFERENCES}

1 Depoux A, Martin S, Karafillakis E, et al. The pandemic of social media panic travels faster than the COVID-19 outbreak. J Travel Med 2020;27:taaa03.

2 Vaezi A, Javanmard SH. Infodemic and risk communication in the era of CoV-19. Adv Biomed Res 2020;9:10.

3 Zarocostas J. How to fight an infodemic. Lancet 2020;395:676.

4 Ferrara E. \#COVID-19 on Twitter: Bots, conspiracies, and social media activism. arXiv 2020.

5 Liu M, Caputi TL, Dredze M, et al. Internet searches for unproven COVID-19 therapies in the United States. JAMA Intern Med 2020;180:1116. 
6 Smout A, Sandle P. Misinformation ruins lives, UK fact-checker says. National Post 2020.

7 lacurci G. Americans have lost $\$ 13.4$ million to fraud linked to Covid-19. CNBC 2020.

8 8. BBC Two. Can I really boost my immune system? [Internet]. London, UK, 2020. Available: https://www.bbc.co.uk/programmes/ articles/1bGNzff3qDWhyXKFchKJb6h/can-i-really-boost-myimmune-system

9 Harvard Health Publishing. How to boost your immune system. Boston: Harvard Health Publishing, 2014. https://www.health. harvard.edu/staying-healthy/how-to-boost-your-immune-system

10 Shi Y, Wang Y, Shao C, et al. COVID-19 infection: the perspectives on immune responses. Cell Death Differ 2020;27:1451-4.

11 Stump S. Oz shares 4 ways to strengthen your immune system. Today, Health \& Wellness, 2020. Available: https://www.today.com/ health/how-boost-your-immunity-dr-oz-shares-advice-coronavirusspreads-t175593

12 Sloan AE, Hutt CA. Repositioning nutraceutical products for growth markets. Nutraceuticals World 2015:9.

13 Nielsen KE. Health beneficial consumer products - status and trends. In: Osborn S, Morley W, eds. Developing food products for consumers with specific dietary needs. Cambridge, MA: Woodhead Publishing, 2016: 15-42.

14 Bursztyn L, Rao A, Roth C. Working paper No. 2020-44. misinformation during a pandemic. Becker Friedman Institute for Economics, 2020. https://bfi.uchicago.edu/wp-content/uploads/BFI WP_202044.pdf

15 Blouin-Genest G, Carignan ME, David MD, et al. COVID-19: Des troubles de stress et d'anxiété bien présents au Québec et au Canada, aggravés par la désinformation. Université de Sherbrooke, 2020. Available: https://www.usherbrooke.ca/actualites/nouvelles/ nouvelles-details/article/42735/

16 Cohen A. Why Canada's response to COVID-19 is so different from that of the U.S. Ottawa Citizen, Opinion/Columnists, 2020

17 Yousif N. Canadians have more faith in government than Americans and Brits and less fear for their lives. Macleans, 2020. Available: https://www.macleans.ca/society/health/canadians-have-more-faithin-government-to-handle-coronavirus-than-americans-and-britsand-less-fear-for-their-lives/

18 Cassa Macedo A, Oliveira Vilela de Faria A, Ghezzi P. Boosting the immune system, from science to myth: analysis the infosphere with Google. Front Med 2019;6:165.

19 Statista. Worldwide desktop market share of leading search engines from January 2010 to January 2020, 2020. Available: https://www. statista.com/statistics/216573/worldwide-market-share-of-searchengines/

20 Mayring P. Qualitative content analysis. Forum: Qualitative Social Research, 2000.

21 Rachul C, Caulfield T. Gordie Howe's Stem Cell 'Miracle': A Qualitative Analysis of News Coverage and Readers' Comments in Newspapers and Sports Websites. Stem Cell Rev Rep 2015;11:667-75.

22 Marcon AR, Murdoch B, Caulfield T. Fake news portrayals of stem cells and stem cell research. Regen Med 2017;12:765-75.
23 Caulfield T, Marcon AR, Murdoch B. Injecting doubt: responding to the naturopathic anti-vaccination rhetoric. J Law Biosci 2017;4:229-49.

24 Rachul C, Rasko JEJ, Caulfield T. Implicit hype? representations of platelet rich plasma in the news media. PLoS One 2017;12:e0182496.

25 Marcon AR, Bieber M, Caulfield T. Representing a "revolution": how the popular press has portrayed personalized medicine. Genet Med 2018;20:950-6.

26 McHugh ML. Interrater reliability: the kappa statistic. Biochem Med 2012;22:276-82.

27 Petrescu P. Google organic click-through rates in 2014. MOZ, 2014. Available: https://moz.com/blog/google-organic-click-through-ratesin-2014

28 HealthifyMe. Top 10 foods to build your immune system, 2020. Available: https://www.healthifyme.com/blog/top-10-foods-to-boostyour-immune-system/

29 Aslam R, Gibbons D, Ghezzi P. Online information on antioxidants: information quality indicators, commercial interests, and ranking by Google. Front Public Health 2017;5:90.

30 Clarke TC, Black LI, Stussman BJ, et al. Trends in the use of complementary health approaches among adults: United States, 2002-2012. National health statistics reports 2015;79:1.

31 Grand View Research. Dietary supplements market size, share \& trends analysis report by ingredient (vitamins, minerals), by form, by application, by end user, by distribution channel, by region, and segment forecasts, 2020 - 2027, 2020. Available: https://www. grandviewresearch.com/industry-analysis/dietary-supplementsmarket

32 Qato DM, Alexander GC, Guadamuz JS, et al. Prevalence of dietary supplement use in US children and adolescents, 2003-2014. JAMA Pediatr 2018;172:780-2.

33 Sundar A, Kardes FR. The role of perceived variability and the health halo effect in nutritional inference and consumption. Psychol Mark 2015;32:512-21.

34 Boyer G, Caulfield T, Green PHR, et al. Promotion of testing for celiac disease and the gluten-free diet among complementary and alternative medicine practitioners. Am J Gastroenterol 2019;114:786-91.

35 Iles IA, Pearson JL, Lindblom E, et al. "Tobacco and Water": Testing the Health Halo Effect of Natural American Spirit Cigarette Ads and Its Relationship with Perceived Absolute Harm and Use Intentions. Health Commun 2020:1-12.

36 Caulfield T. Microbiome research needs a gut check. Folio, 2019. Available: https://www.folio.ca/commentary-microbiome-researchneeds-a-gut-check/

37 Murdoch B, Zarzeczny A, Caulfield T. Exploiting science? A systematic analysis of complementary and alternative medicine clinic websites' marketing of stem cell therapies. BMJ Open 2018;8:e019414.

38 Shearer E, Gottfried J. News use across social media platforms 2017. Pew Research Center 2017;7:2017. 